\title{
SISTEM KOMPUTERISASI PENGOLAHAN BUKU INDUK PEGAWAI PADA UPT DINAS PENDIDIKAN PEMUDA DAN OLAHRAGA KECAMATAN BANJARMANGU BERBASIS PHP DAN MYSQL
}

\author{
Elisa Usada ${ }^{1}$, Irwan Susanto ${ }^{2}$, Meliana Fera Kurniasih ${ }^{3}$ \\ ${ }^{1,2,3}$ Program Studi Diploma III Teknik Telekomunikasi, Purwokerto \\ elisa@akatelsp.ac.id, ${ }^{2}$ irwan@akatelsp.ac.id
}

\begin{abstract}
ABSTRAK
Permasalahan yang akan dibahas adalah bagaimana membuat sistem pengolahan buku induk pegawai di UPT Dinas Pendidikan Pemuda dan Olahraga Kecamatan Banjarmangu berbasis PHP dan MySQL. Sistem pengolahan buku induk pegawai berbasis PHP dan MySQL ini dirancang komputerisasi menggunakan PHP dan database MySQL dengan tujuan agar pengolahan data pegawai di UPT Dinas Pendidikan Pemuda dan Olahraga Kecamatan Banjarmangu dapat terpusat. Metode penelitian yang digunakan adalah menggunakan metode waterfall. Sistem pengolahan buku induk pegawai ini menggunakan jaringan client server dan dapat diakses oleh administrator dan Kepala UPT dan Pegawai. Kelebihan dari sistem pengolahan ini adalah dilindungi password dan hak akses yang berbeda untuk setiap user sehingga keamanan data dapat terjamin, sedangkan kekurangannya adalah program yang dihasilkan belum maksimal karena mengkhususkan data pegawai pada buku induk saja. Saran dari sistem pengolahan ini yaitu pengembangan dari segi keamanan data, kelengkapan data, dan ketelitian sistem dalam input data untuk mengurangi kesalahan.
\end{abstract}

Kata kunci : SIM Buku Induk Pegawai, PHP, MySQL

\section{PENDAHULUAN}

Perkembangan teknologi bidang teknik informatika saat ini memungkinkan semua bidang kehidupan manusia dapat semakin ringan dikerjakan dengan bantuan komputer. Peningkatan kebutuhan komputer ini perlu mendapat perhatian dan penanganan yang tepat sehingga hasil yang diperoleh sesuai dengan tujuan yang diinginkan.

Pengolahan data pegawai di Dinas Pendidikan Pemuda dan Olah Raga Kecamatan Banjarmangu masih dilakukan secara manual, dimana ketergantungan pada lembaran-lembaran kertas sebagai media penyimpanan data yang kurang efektif dan kurang efisien dari segi waktu, tenaga dan jaminan akan kebenaran dan keutuhan data yang akan diproses. Melihat kekurangan pengolahan data secara manual tersebut, maka dibutuhkan sebuah sistem yang mampu melakukan pengolahan data secara cepat sesuai dengan pembaharuan (up to date) perkembangan kebutuhan informasi.

Oleh karena itu, perlu dibuat suatu sistem pengolahan data pegawai berbasis komputer yang dapat mengatasi kelemahan dan kekurangan dari sistem pengolahan data sebelumnya. Sistem pengolahan data ini dapat dilakukan dengan cepat, meskipun jumlah data yang dimasukan relatif banyak dan keakuratan perhitungan dan laporan dapat dicapai semaksimal mungkin sehingga kesalahan dalam memasukan dan perhitungan data relatif kecil, dengan proses dalam pengerjaan dan penyelesaian suatu laporan akan lebih baik. Oleh karena itu, penulis mencoba untuk memecahkan permasalahan tersebut dengan menerapkan sistem pengolahan buku induk pegawai berbasis komputer dengan menggunakan bahasa pemrograman Web PHP dan MySQL yang diaplikasikan Dreamweaver. 
Atas dasar inilah penulis mencoba membantu untuk mengubah sistem pengolahan yang telah ada sebelumnya, sehingga mempermudah semua pihak yang membutuhkan segala informasi data pegawai yang ada di Dinas Pendidikan Pemuda dan Olah Raga Kecamatan Banjarmangu.

\section{METODOLOGI PENELITIAN}

Untuk menyusun tugas akhir ini penulis melakukan penerapan metode penelitian dalam memperoleh data yang dibutuhkan sehingga penyusunan tugas akhir ini dapat diselesaikan dengan baik. Metode Penelitian yang digunakan adalah Waterfall model

Waterfall model adalah sebuah metode pengembangan software yang bersifat sekuensial dan terdiri dari 5 tahap yang saling terkait dan mempengaruhi (Simarmata 2010). Keterkaitan dan pengaruh antar tahap ini ada karena output sebuah tahap dalam Waterfall merupakan input bagi tahap berikutnya, dengan demikian ketidaksempurnaan hasil pelaksanaan tahap sebelumnya adalah awal ketidaksempurnaan tahap berikutnya. Penjelasan dari masing-masing tahap dari Waterfall model tersebut adalah:

a. Analisa kebutuhan.

Analisa kebutuhan merupakan tahap pertama yang menjadi dasar proses pembuatan suatu sistem aplikasi selanjutnya. Kelancaran proses pembuatan sistem aplikasi secara keseluruhan dan kelengkapan fitur sistem aplikasi yang dihasilkan sangat tergantung pada hasil analisa kebutuhan ini. Analisa kebutuhan dibuat dengan melakukan beberapa metode pengumpulan data yaitu:

\section{1) Interview}

Pengumpulan bahan dengan cara interview secara langsung dengan nara sumber untuk dapat mempeoleh informasi berupa fakta atau pendapat dari masalah yang akan dibahas. Penulis melakukan observasi dengan mengamati langsung proses dan pelayanan pada

\section{2) Observasi}

Bagian kepegawaian yang ada di UPT Dinas Pendidikan Pemuda dan Olah Raga Kecamatan Banjarmangu.

\section{3) Studi Literature}

Data yang diperoleh berasal dari referensi yang berkaitan dengan pemrograman PHP, Database, MySQL agar dapat memahami masalah yang akan dibahas.

\section{b. Desain sistem.}

Desain sistem merupakan tahap penyusunan proses, data, aliran proses dan hubungan antar data yang paling optimal untuk menjalankan proses pembuatan sistem aplikasi dan memenuhi kebutuhan yang sesuai dengan hasil analisa kebutuhan.

c. Penulisan kode program.

Penulisan kode program merupakan tahap penerjemahan desain sistem yang telah dibuat ke dalam bentuk perintah-perintah yang dimengerti komputer dengan menggunakan bahasa pemrograman dan database tertentu. Bahasa pemrograman yang digunakan yaitu PHP untuk pembuatan program dalam kategori Web Application dan database yang digunakan 
adalah MySQL untuk kebutuhan penyimpanan data.

d. Pengujian program.

Pengujian program dilakukan untuk memastikan bahwa program yang dibuat telah sesuai dengan desainnya dan semua fungsi dapat dipergunakan dengan baik tanpa ada kesalahan.

\section{HASIL DAN PEMBAHASAN}

\section{a. Analisa Kebutuhan}

Tahap pertama yang menjadi dasar proses pembuatan suatu sistem aplikasi selanjutnya adalah analisa kebutuhan. Proses pembuatan suatu aplikasi atau sistem tentunya membutuhkan alat-alat pendukung, baik hardware maupun software (Kristanto I. H., 1993,1994,2004) Beberapa instrumen yang digunakan dalam pembuatan aplikasi dengan memanfaatkan fasilitas yang telah ada dan masih dapat memenuhi kebutuhan, yaitu:

a. Kebutuhan hardware dan software

b. Beberapa data yang akan dimasukkan ke dalam sistem pengolahan buku induk pegawai ini. Untuk data yang diperlukan yaitu data pegawai.

\section{b. Desain Sistem dan Pembuatan Program}

\section{1) Perancangan Database}

Sebelum membuat database penulis membuat DFD (Data Flow Diagram) yang merupakan suatu alat untuk memudahkan dalam pengambaran suatu sistem yang ada atau sistem yang akan dibuat secara logika tanpa memperhatikan lingkungan fisik yang data tersebut mengalir atau lingkungan fisik yang data tersebut akan disimpan. Setelah itu, penulis melakukan normalisasi untuk menghindari penumpukkan data.

$$
\text { - Tabel Pegawai }
$$

Data pegawai disimpan di tabel ini dengan NIP sebagai primary key.

- Tabel Pendidikan Umum

Tabel pendidikan umum digunakan untuk menyimpan data-data riwayat pendidikan umum dari pegawai dengan kd_pend_umum sebagai primary key.

- Tabel Kursus

Tabel kursus digunakan untuk menyimpan data-data riwayat pendidikan kursus dari pegawai dengan no_sertifikat sebagai primary key.

- Tabel Istri/Suami

Tabel issu digunakan untuk menyimpan datadata Istri/suami dari pegawai dengan karissu sebagai primary key.

- Tabel Anak

Tabel anak digunakan untuk meniyimpan datadata anak.

- Tabel Riwayat Golongan

Tabel riwayat golongan digunakan untuk menyimpan data-data riwayat golongan dari pegawai.

- Tabel Riwayat Jabatan

Tabel riwayat jabatan digunakan untuk menyimpan data-data riwayat jabatan dari pegawai.

- Tabel Agama

Tabel agama berisi tentang agama yang dianut oleh pegawai.

- Tabel Golongan 
Tabel golongan digunakan untuk menyimpan data golongan dari pegawai.

- Tabel Instansi Kerja

Tabel ini digunakan untuk membantu dalam penyimpanan data instansi kerja dari masingmasing pegawai.

- Tabel Set Pendidikan

Tabel ini digunakan untuk membantu dalam penyimpanan data pendidikan dari pegawai.

- Tabel Jurusan

Tabel ini digunakan untuk membantu dalam penyimpanan data jurusan dari pegawai.

\section{2) Koneksi Database}

Koneksi database dalam bahasan kali ini adalah melakukan pengaturan untuk menghubungkan interface program yang akan dibuat dengan database yang digunakan oleh sistem. Koneksi database yang dilakukan adalah dengan membuat satu file yang berisi bahasa pemrograman web PHP yang kemudian disimpan dalam suatu lokasi dalam folder.

\section{3) Perancangan Interface Program}

Perancangan Interface dalam bahasan kali ini adalah membuat perencanaan terhadap tampilan antarmuka program yang digunakan administrator dalam melakukan mengolahn data pegawai yang dibutuhkan dalam sistem. Rencana perancangan antarmuka program adalah menampilkan halaman depan dan halaman utama.

\section{4) Perancangan Jaringan}

Perancangan jaringan dilakukan dengan cara:

- Pemilihan Topologi

- Pemilihan Perangkat

- Alokasi IP Address

- Perancangan Jaringan dari Sisi Server dan Sisi Client

\section{PENGUJIAN}

Setelah pembuatan program, langkah selanjutnya adalah pengujian dari program yang telah dibuat. Jenis pengujian yang dilakukan menggunakan jenis pengujian fungsional (functional testing). Jenis pengujian ini adalah perangkat lunak diuji untuk persyaratan fungsional. Pengujian dalam bentuk tertulis untuk memeriksa apakah aplikasi berjalan seperti yang diharapkan. Pengujian fungsional meliputi seberapa baik sistem melaksanakan fungsinya (Simarmata 2010).

\section{a. Pengujian Sistem Pengolahan Buku Induk Pegawai}

Pengujian dilakukan pada setiap menu yang ada dalam program. Hasil dari pengujian yang telah dilakukan terhadap program aplikasi sistem pengolahan buku induk pegawai pada UPT Dinas Pendidikan Pemuda dan Olahraga Kecamatan Banjarmangu ini dicatat berdasarkan menu dan fungsi-fungsi yang ada di dalamnya. 
Tabel 1. Pengujian Sistem Pengolahan Buku Induk Pegawai

\begin{tabular}{|c|c|c|c|c|}
\hline \multirow{2}{*}{ No. } & \multirow{2}{*}{ Menu yang Diujikan } & \multirow{2}{*}{ Proses } & \multicolumn{2}{|c|}{ Hasil } \\
\hline & & & Berhasil & Gagal \\
\hline 1 & Data Pegawai & Simpan data (input dan update) & $\checkmark$ & \\
\hline 2 & Data Pegawai & Hapus data & $\checkmark$ & \\
\hline 3 & Data Pegawai & $\begin{array}{l}\text { Cari data berdasarkan NIP, Nama } \\
\text { dan Instansi Tempat Kerja }\end{array}$ & $\checkmark$ & \\
\hline 4 & $\begin{array}{l}\text { Data Pendidikan } \\
\text { Umum }\end{array}$ & $\begin{array}{l}\text { Simpan data (input secara } \\
\text { simultan dan update) }\end{array}$ & $\checkmark$ & \\
\hline 5 & $\begin{array}{l}\text { Data Pendidikan } \\
\text { Umum }\end{array}$ & Hapus data & $\checkmark$ & \\
\hline 6 & $\begin{array}{l}\text { Data Pendidikan } \\
\text { Umum }\end{array}$ & Cari data berdasarkan NIP & $\checkmark$ & \\
\hline 7 & $\begin{array}{l}\text { Data Pelatihan atau } \\
\text { Kursus }\end{array}$ & $\begin{array}{l}\text { Simpan data (input secara } \\
\text { simultan dan update) }\end{array}$ & $\checkmark$ & \\
\hline 8 & $\begin{array}{l}\text { Data Pelatihan atau } \\
\text { Kursus }\end{array}$ & Hapus data & $\checkmark$ & \\
\hline 9 & $\begin{array}{l}\text { Data Pelatihan atau } \\
\text { Kursus }\end{array}$ & Cari data berdasarkan NIP & $\checkmark$ & \\
\hline 10 & Data Istri atau Suami & Simpan data (input dan update) & $\checkmark$ & \\
\hline 11 & Data Istri atau Suami & Hapus data & $\checkmark$ & \\
\hline 12 & Data Istri atau Suami & $\begin{array}{l}\text { Cari data berdasarkan No. Karis } \\
\text { atau Karsu (Karissu) }\end{array}$ & $\checkmark$ & \\
\hline 13 & Data Anak & $\begin{array}{l}\text { Simpan data (input secara } \\
\text { simultan dan update) }\end{array}$ & $\checkmark$ & \\
\hline 14 & Data Anak & Hapus data & $\checkmark$ & \\
\hline 15 & Data Anak & $\begin{array}{l}\text { Cari data berdasarkan No. Karis } \\
\text { atau Karsu (Karissu) }\end{array}$ & $\checkmark$ & \\
\hline 16 & Laporan Buku Induk & $\begin{array}{l}\text { Menampilkan data tiap pegawai } \\
\text { berdasarkan NIP yang akan } \\
\text { dicetak }\end{array}$ & $\checkmark$ & \\
\hline 17 & $\begin{array}{l}\text { Laporan Data } \\
\text { Pegawai }\end{array}$ & $\begin{array}{l}\text { Menampilkan rekap data pegawai } \\
\text { berdasarkan instansi tempat kerja } \\
\text { masing-masing yang akan dicetak }\end{array}$ & $\checkmark$ & \\
\hline 18 & Backup Database & Download Database & $\checkmark$ & \\
\hline 19 & Data User & Simpan data (input) & $\checkmark$ & \\
\hline 20 & Data User & Hapus data & $\checkmark$ & \\
\hline 21 & Agama & Simpan data (input) & $\checkmark$ & \\
\hline 22 & Agama & Hapus data & $\checkmark$ & \\
\hline 23 & Set Pendidikan & Simpan data (input) & $\checkmark$ & \\
\hline 24 & Set Pendidikan & Hapus data & $\checkmark$ & \\
\hline 25 & Jurusan & Simpan data (input) & $\checkmark$ & \\
\hline 26 & Jurusan & Hapus data & $\checkmark$ & \\
\hline
\end{tabular}




\section{b. Pengujian Interface Program}

Pengujian ini dilakukan untuk memastikan apakah interface program dapat menampilkan informasi sesuai fungsi masing-masing menu yang telah diujikan sebelumnya sesuai dengan layout program yang telah dirancang.

- Tampilan Halaman Utama

- Halaman Login

Halaman login adalah halaman yang digunakan pada saat pertama kali pengguna memakai sistem aplikasi ini. Pengguna sistem dapat masuk kedalam sistem jika pengguna memasukkan username dan password lalu memilih tombol login. Data yang sudah dimasukkan akan dieksekusi oleh sistem dan akan manampilkan halaman sesuai dengan level user.

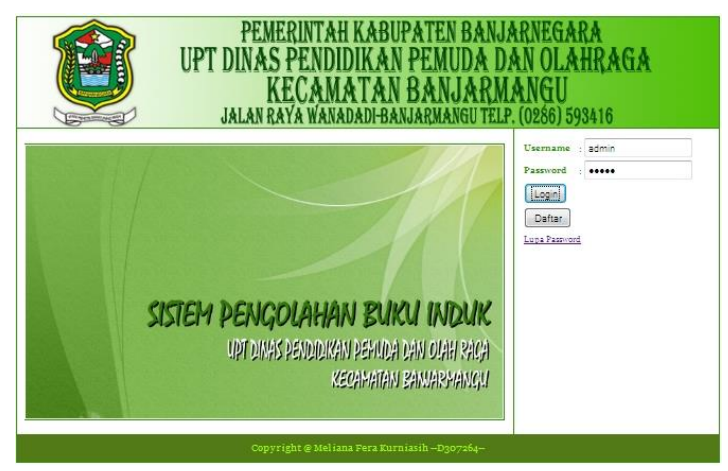

Gambar 1 Tampilan Halaman Login

- Tampilan Halaman untuk Admin

Halaman admin adalah halaman yang digunakan untuk mengelola data-data pegawai. Halaman admin akan muncul setelah memasukkan username dan password untuk login sebagai administrator dengan benar pada halaman utama, akan tampil halaman untuk admin. Pada halaman admin disediakan menu- menu yang meliputi home, olah data, laporan backup database, pengaturan, dan keluar.

- Halaman untuk Kepala UPT

Halaman ini khusus untuk Kepala UPT. Di halaman ini Kepala UPT dapat melihat data diri dan melihat laporan data pegawai. Selain itu juga dapat mengubah akunya sendiri.

- Halaman untuk User biasa

Halaman ini khusus untuk user. Di halaman ini seorang Pegawai dapat melihat informasi tentang data diri Pegawai tersebut. Selain itu juga dapat mengubah akunya sendiri.

\section{c. Pengujian Jaringan}

Pengujian jaringan dilakukan untuk mengetahui koneksi jaringan yang ada dengan melakukan perintah ping ke IP server dari client dan ke client dari server pada command promp.

\section{KESIMPULAN}

\section{a. Kelebihan Sistem Pengolahan Buku Induk}

1) Sistem pengolahan buku induk pegawai ini dirancang sederhana dengan tujuan untuk mempermudah dalam pengelolaan data pegawai.

2) Sistem pengolahan buku induk pegawai ini dilindungi password dan hak akses yang berbeda untuk setiap user sehingga keamanan data dapat terjamin.

3) Database menjadi terpusat karena tersimpan dalam satu sisi server.

\section{b. Kekurangan Sistem Pengolahan Buku} Induk 
1) Program yang dihasilkan belum memiliki kelengkapan data dengan aslinya karena mengkhususkan data pegawai untuk buku induk saja.

2) Mengingat keterbatasan waktu dan kemampuan tentunya masih terdapat hal yang masih belum tampil maksimal, yaitu masih terdapat error pada form backup database. Fasilitas backup database hanya bisa dilakukan pada komputer yang menggunakan sistem operasi Windows XP.

\section{DAFTAR PUSTAKA}

1. Budi Hermawan. 2009. 1 Diakses pada 09 Oktober 2010.

2. Kristanto, I. H. $(1993,1994,2004)$.

Konsep \& Perancangan Database.

Yogyakarta: ANDI.

3. Fathansyah, I. (2002). Basis Data. Bandung: Informatika Bandung.

4. Simarmata, J. (2007). Perancangan Basis Data. Yogyakarta: ANDI.

5. Kadir, A. (2009). Dasar Perancangan \& Implementasi. Yogyakarta: ANDI.

6. Suprianto, D. (2008). Buku Pintar Pemrograman PHP. Bandung: OASE Media.
7. Kristanto, A. (2010). Kupas Tuntas $P H P \& M y S Q L$. Klaten: Cable Book.

8. Yusnita, Sri (2007). Popularitas PHP. Diakses pada 13 Oktober 2010: HYPERLINK "http://students.ee.itb.ac.id/ yusnita/ php.pdf" http://students.ee.itb.ac.id/ yusnita/php .pdf

9. Kristanto, A. (2003). Jaringan Komputer. Yogyakarta: Graha Ilmu.

10. Sofana, I. (2008). Membangun Jaringan Komputer. Bandung: Informatika Bandung.

11. Hakim, L. (2008). Membongkar Trik Rahasia Para Master PHP. Yogyakarta: LOKOMEDIA.

12. Simarmata, J. (2010). Rekayasa Perangkat Lunak. Yogyakarta: ANDI.

13. Fatkhan Site's. 2009. Jaringan Peer to Peer.

http://www.amhusite.co.cc/2009/05/jar ingan-peer-to-peer.html Diakses pada 26 Oktober 2010. 